Competing Interests:

None declared.

Ethical approval:

Not applicable.

Author's contribution: $B M-T^{1}$ designed and coordinated this research and prepared the manuscript in entirety.

\section{Funding:}

None declared.

\section{Acknowledgements:} $B M-T^{1}$ acknowledges John Foster and Peter Earl for their feedback and suggestions on this paper.

\title{
Anarchy, Blockchain and Utopia: A theory of political-socioeconomic systems organised using Blockchain
}

\author{
Dr. Brendan Markey-Towler ${ }^{1}$ PhD \\ School of Economics, University of Queensland, Australia
}

Correspondence: brendan.markeytowler@uqconnect.edu.au

Received: 19 February 2018 Accepted: 17 March 2018 Published: 19 March 2018

\begin{abstract}
Blockchain technology makes it more feasible for individuals to exit political-socioeconomic systems at the level of the system itself and elect to accede freely to institutional systems which formulate, promulgate, keep and verify institutions and public records without a centralised authority. This essay investigates the dynamic of such a society in which political-socioeconomic systems may be organised using blockchain technology. We propose a theory of society as an evolutionary system in which the unit of selection is the institutional system associated with a particular blockchain or the state and selection pressures are applied by individuals deciding to interact within them and have their interactions entered into the public record. We establish the conditions under which institutions will thus be selected by considering the limits to substitutability and discover that any institutional system must meet requirements and provide sufficient complementarities in order to be selected and retained by the evolutionary process.
\end{abstract}

Keywords: blockechain, sociology, institutions, anarchy, utopia

JEL Classifications: D02, D71, H11, P16, P48, P50

\section{Introduction: the anarchist utopia}

The basic vision of anarchism - if indeed there can be one for such a diffuse and subtle mode of political thought - is of a society entirely free of the State and all its violence and coercion. The utopia of the anarchist is no free-for-all war of all against all either. Instead, it is a society in which individuals are entirely free to elect to associate themselves with others and interact with them according to a set of rules to which those others agree.

The anarchists have been crushed throughout history by those who wish the state to hold a monopoly over defining what is right and proper behavior, and those who fear what might happen if individuals were free to associate and interact as they wished (Marshall, 1992). Power ultimately relies on submission as Etienne La Boetie showed in On Voluntary Servitude, but as yet it has been found infeasible for a sufficiently large portion of society to repudiate the coercion of the state and associate freely to neuter the state's ability to use violence effectively to remove those who do from society. Yet now, even while the state exists all-powerful, the technology which might allow for such large-scale action is emerging in the form of the blockchain. On the face of it a mundane and boring technology for bookkeeping, blockchain is actually revolutionary because it makes the anarchist utopia a more realisable dream than has ever before been possible. At the very least it provides the strongest challenge ever posed to the monopoly of the state over the promulgation, formation, keeping and verification of institutions and the public record. The purpose of this essay is to investigate the conditions under which this might occur, and the dynamics of a society organised using blockchain technologies.

In the next section, we will consider blockchain and how, as a distributed ledger technology, it provides a platform which might constitute the foundation of entire institutional systems which might compete with the state, and at the very least make exit from existing political-socioeconomic systems more feasible than ever before. We then investigate the dynamics of such a society as would be organised by blockchain by proposing a theory of society as an evolutionary system in which the unit of selection is an institutional system associated with a particular blockchain or the State and establish the properties of an institutional 
system which is likely to be selected and retained by the evolutionary process. We conclude by considering the likely outcome of this process and what will be required for the anarchist dream of a society formed by free association and interaction, or at least a serious challenge to the hegemony of the State over the institutional system to be realised.

\section{What is Blockchain technology and why is it so important}

Blockchain technology is a distributed ledger technology (Davidson, De Filippi and Potts, forthcoming; 2016; Catalini and Gans, 2017). What that means is that it is a technology by which a group of people can come to a consensus on the keeping of a record - a "book" - without requiring the surrender of their collective assent to a centralised authority. A public record can be kept without the requirement of a public authority.

The software, operating on the internet, registers all of the interactions which occur between individuals interacting using the corresponding medium of interaction. Individuals are rewarded for processing and verifying that information by building it into a record and then solving a mathematical problem posed at the end of the processing which allows all others to verify that the record has been correctly compiled. As each verifies that the record has been correctly compiled, the block of records is then added to a chain of such records - the blockchain - of which every single node in the network keeps a copy. Each individual has a private key which allows them to decrypt and access that portion of the blockchain which records their own interactions. The record of interactions is thus distributed among the entire network (making it extremely and increasingly secure) and it is updated and verified by the network as a whole, without the need for a centralised authority.

Now that sounds relatively prosaic: blockchain is a social technology which allows a collective to write a book and update it - a book-keeping technology. It is anything but prosaic. The keeping of records which can be publicly verified is the very foundation of our advanced political-socioeconomic systems.

The first systematic study of the economics of recordkeeping was provided (somewhat unwittingly) by John Commons (1924) in his Legal Foundations of Capitalism. What he showed there was that the rise of humanity from the oppression of subsistence by economic development was accompanied by the emergence of the institutions (rules for thought, action and interaction) of the law, especially the law of contract and property. Only once the enforcement of property and contract became a greater surety could the expectations of reciprocity, of quid pro quo, and expectations of libertas (the right to use property) necessary for large scale market interaction be supported. The laws of contract and property were a precondition for the development of the capital base and technologies embodied within it which drove the industrial revolution (Landes, 1969) and was a guarantor of the emerging "bourgeois virtues" supporting exchange and enterprise (McCloskey, 2006).

The laws of contract and property demand the keeping of verifiable records to function well - without records establishing the alternative facts, a judge relies entirely upon the law of equity. Hence, since the very basis for our market economies is the law of contract and property, and these rely on the keeping of verifiable records, our entire economic system at the very least relies on the keeping of verified public records.

Really, we know that not only our entire economic system but also our entire political and social system relies on institutional structures and the recording of interactions within them in a public record as well. Institutions give us the basis for interaction in political socioeconomic systems by establishing the proper ways to act and interact in society (Hamilton, 1919; Williamson, 1985; North, 1990; Ostrom, 1990). Institutions establish the social positions individuals might occupy which are associated with rights, obligations and empowerments to act in particular situations (Searle, 2010; Lawson 2015). Public records inform us of, and verify, who occupies those positions. The law, for instance, which consists of rules for proper interaction and which deputises those who may use violence and coercion against those who transgress them (Hart, 1961) is predicated upon the keeping of public records: parliamentary statutes, executive regulations and rules, royal proclamations-in-council, judicial decisions.

Traditionally, the formulation, promulgation, keeping, verification and enforcement of public records of institutions and interaction according to them has been a process conferred exclusively upon and monopolised by the government. Now of course, when it was difficult to communicate with the entirety of humanity instantaneously this was efficient enough. But this efficiency is gained at the cost of creating a nexus of power which might be used by those occupying it for extortion by withholding the entering

Blockchain technology, by operating on the internet, largely eliminates the cost of communication even at the scale of populations. Since the public record is kept by everyone and updated by collective assent and any individual is incentivised to update it, there is no nexus of power which may be exercised to corrupt or use the public record as a tool of extortion. The cost of this gain is that the process is energy-intensive and requires significant digital storage capacities. 
What is revolutionary about this technology therefore, is that it makes even yet more viable what Albert Hirschman (1970) called the "exit" response to decline in organisations. when faced with a system in which one's needs and desires are not being met, one has, in theory, two options. one may voice one's concerns with the system in the hope that the decision-makers in the system might address them by changing the system. or one may exit the system and join one more amenable to one's objectives. Hirschman's theory, of course, was that in the absence of loyalty, exit would become increasingly preferable as the response to voice on the part of decision makers within the system became less and less.

As the RMIT school of thought has rightly recognised (Berg and Berg, 2017; MacDonald, 2015b), the blockchain makes exit more viable at the level of entire political-socioeconomic systems by making possible (in principle at least) the acceding to a non-centralised political-socioeconomic system (MacDonald, 2015a). The government is one means by which a set of institutions may be formulated, kept, promulgated and verified and public records of interactions under their rubric kept. The blockchain provides another, and one which does not require the surrendering of assent to the institutional structure and public record to a centralised authority.

What does this mean more practically? Well we have already seen the emergence of Bitcoin as a public record of transactions and holdings of a medium of exchange. But blockchain is no mere money-counting device. Ethereum has already pioneered the keeping of contract records, and the striking of "smart" contracts which execute automatically. Horizon State is among a number of companies pioneering the use of Blockchain technology as a means of keeping voting records. Blockchains allow us to formulate, promulgate, keep and verify institutional structures and keep a public record of interactions within them which have the potential to revolutionise the financial sector and the way we conduct market exchange (MacDonald, Allen and Potts, 2016), the way we strike contracts and collaborate (Davidson, De Filippi and Potts, forthcoming; 2016) and the very way we govern ourselves as collectives constrained by agreeing particular rules for interaction (Allen, Berg, Lane and Potts, 2017).

But what if we went further? What if we used it as a means of issuing shares or keeping store credit as a "token"? What if it were used to build collectively funded and governed welfare or healthcare provision systems - modern friendly societies? What if it were used as a means of registering and verifying one's educational attainments or qualifications? What if it were used as a means of registering births, deaths and marriages?
No blockchain compels people by force (at present) to join it, interact according to its interactions and record those interactions therein, and by definition it requires the assent of the collective to function. As Etienne La Boetie showed in On Voluntary Servitude, power is ultimately submitted to rather than extended, and one might simply cease to interact by use of a particular Blockchain if one comes to repudiate its institutional structure, so it is in the final estimation a matter of choice to acquiesce to the institutions associated with any particular blockchain.

Blockchain technology therefore offers the possibility of finally realising the anarchist dream (Marshall, 1992) - a society which is composed of groups formed entirely by mutual association and absent violence and coercion. Blockchain might provide the missing link which allows for the formation of large-scale (therefore feasible) societies with institutions formulated and promulgated and records kept and verified collectively. Quite a utopia.

This is no mere matter of intellectual curiosity. The possibility of exit on the societal level is now a matter of desperate practicality. Even in the "Western" democracies (Australia is as good an example as any), the nexus of power has become hopelessly corrupt as the laws have finally reached the point of having to resist and repress the basic human tendency to form groups for mutual assistance (Murray and Frijters, 2017). Upward mobility has eroded drastically as the nexus of power has become ever more impervious to the Voice of all but those with the resources necessary to sustain lengthy campaigns - Mancur Olsen's (1965) nightmare of socio-political capture by vocal minorities prevails. The citizen seeking to survive and thrive is increasingly left with their last right - the right to repudiate the system of political-socioeconomy in its entirety and accede to a new system formed of voluntary association.

But how does such a system function? What does a society formed of individuals all, in the final estimation, voluntarily conducting their political-socioeconomic interactions in the medium they choose "look" like? The answer is provided by evolutionary institutional political economy and economic psychology.

\section{A theory of political-socioeconomic systems organised using the Blockchain}

Take a population of people and imagine that, in addition to the institutions of states, there exists a set of institutional systems associated with various blockchains in which interactions governed by those institutions are recorded. Institutional systems are to be understood as a set of rules which guide thought and action and stipulate the proper form of interaction in society (Hodgson, 1998; 2004; Hodgson and Knudsen, 2010). We can imagine the population of people to 
be partitioned into demes (Hartley and Potts, 2014) according to the institutional systems by which they elect to conduct their political-socioeconomic affairs and the corresponding blockchain on which interactions within the confines of those institutions are recorded and verified. The residual of the population who do not elect to accede to any institutional system with a corresponding blockchain either elect to, or by default, conduct their affairs under the institutional system, and have them recorded within the public records, of the State.

An individual leaves the institutional structure and its corresponding deme (defined by its corresponding blockchain or the institutions of the state) if they elect to cease interacting according to its institutions with others in the deme, therefore cease to have their political-socioeconomic interactions entered into the public record of blockchain or state, and thus repudiate that institutional structure. An individual cease to be part of a deme, an institutional system, when they elect to exit it rather than exercise voice in an attempt to change it. Thus, in principle at least, we have movement between demes and a sort of competition between them for adherents. Institutional systems compete to have individuals elect to adhere to their institutions, rules for interaction, and have their interactions entered on the public record.

Such a society is, in principle at least, anarchic. In principle individuals elect to adhere to a particular set of institutional systems and not others, provided the state or blockchain deme does not coerce or compel. It is a society based on mutual association and elective submission to rules for interaction.

\subsection{Society as an evolutionary system}

Now, because of the tendency introduced for an a priori set of institutional systems to be reconciled into posteriori set through the interactions of individuals, such a society is also an evolutionary system (Price, 1970; 1972a; 1972b; Page and Nowak, 2002). It is a society therefore subject to variation of institutional structures, selection between institutional structures and their retention (Nelson and Winter, 1982; Metcalfe 1998; 2008; Dopfer and Potts, 2007; Witt, 2008; Hodgson and Knudsen, 2010, Markey-Towler 2017). It is a society, in a sense, where various visions of utopia are competing for adherents (Almudi, FatasVillafranca, Izquierdo and Potts, 2017; Almudi, FatasVillafranca and Potts, 2017). The unit of selection in this evolutionary process is the institutional system associated with any given blockchain (or the State), and the process of selection is the decision of individuals in society to conduct their political-socioeconomic affairs therein and have their interactions recorded on its blockchain (or by the State) as part of the public record.
Selection pressures are therefore exerted upon institutions by the behavioural change of individuals, specifically, their decision to conduct their politicalsocioeconomic affairs in this institutional system or that. When individuals choose exit over voice in the presence of whatever displeasure with their current system, that system is deselected in favour of some other system to which those individuals accede. So, if we wish to understand the characteristics of institutional systems which will likely be retained by the this process we must seek to understand the conditions under which individuals will opt to exit the one institutional system and accede to another.

\subsection{The limits to substitution and the selection and retention of institutional systems}

Here we are assisted by economic psychology, especially that of Peter Earl (1986a, b; 1990, 1995; 2017) (formalised in Markey-Towler (2017b, c; forthcoming)) which identifies exactly what such conditions are and the limits of their application. Individuals may be induced to exit the one system and accede to the other (provided they perceive the opportunity to do so and have sufficient knowledge ) if a state of substitutability exists between them. That is, an individual will exit one system and accede to another if there exists a state in which they expect that outcomes of roughly equivalent preferability will obtain as a result. They may then be induced to substitute systems.

It is, perhaps, easier to establish conditions for retention by reference to what may cause a state of substitutability to not exist and therefore to establish the limits of institutional competition. This will be the case if there does not exist a state of substitutability between any two institutional systems, if the one cannot be substituted for the other without a significant change in the preferability of expected outcomes. There are two reasons this might be the case; either two institutional systems are basically non-substitutable, or some complementarity is realised in the one which is not realised in the other.

\subsection{Non-substitutability: institutional systems must meet requirements}

Basic non-substitutability exists when people aren't concerned with what economists call "tradeoffs" but are instead applying "cutoffs", applying requirements which must be met by the courses of action available to them before they will consider taking them. Individuals do this any time they are applying simple rules to eliminate alternative courses of action rather than making complex considerations of tradeoffs. So, in order to survive and be retained by the evolutionary process, an institutional system and the blockchain recording interactions according to it (or the state) must meet requirements individuals impose on any 
institutional system.

It isn't difficult to imagine what such requirements might be. To interact in society, we must be guaranteed a certain reciprocity and security with respect to exchange and property. Traditionally this has been underwritten by the violence and coercion of the state, but the most basic of anarchist theories recognises that there are other non-violent means of enforcement which involve exclusion (Ackerman and Krueger, 1994). The institutional system must therefore be sufficiently exclusionary toward those unwilling to abide by its institutional structure. To interact in society, we must also be able to use any technologies or artefacts which facilitate such interaction. The institutional system must therefore be sufficiently easy to interact and keep records within. Finally, to interact in society requires a certain degree of libertas - the freedom to use one's property. So, one must be able to keep records of one's property and interactions sufficient to prove their existence which is difficult as possible to manipulate or destroy. The institutional system must therefore be secure from theft, corruption and manipulation.

What is interesting is that technically speaking, blockchain was designed to meet the first (reciprocity and security) and third requirements (integrity and retention), and massive advances are being made with respect to the second. The state, on the other hand, is increasingly providing evidence that it can meet none, and that as through all history, it cannot overcome the innate corruption of the human individual if they occupy a nexus of power by being the keeper of the public record of political-socioeconomic interaction. The limits to substitutability between state and blockchain at this level are increasingly psychological and therefore liable to collapse.

\subsection{Complementarity: institutions must be integrated}

A more potent barrier to substitutability between institutional systems is the existence of complementarity. Complementarity exists when the taking of two courses of action together is more preferable than taking either alone. The ability to do so might therefore be decisive for the existence of a state of substitutability, which is to say that the feasibility of a particular course of action might be decisive for behavioural change insofar as it may be taken together with others.

Complementarity presents a more imposing barrier to substitution and competition than basic nonsubstitutability as regards institutional systems. Despite appearances, political-socioeconomic interactions are not the totality of our existence. Even social media has not eliminated the coexistence of a private sphere alongside the public sphere in which our politicalsocioeconomic interactions occur (Habermas, 1962). It is, therefore, in all likelihood a major consideration for a large part of the population whether or not they may conduct and have entered on the public record all or at least a large portion of their political-socioeconomic interactions within the context of a single institutional system. One definitely important aspect of institutional systems then is the range of political-socioeconomic interactions which may be conducted within them and integrated into the public record.

It matters then that I might within the one institutional system with its associated public record at once purchase my groceries, manage my investment portfolio, strike contracts, be paid for my services, pay my rent or mortgage, and register my property in the public record. It also matters that I might be able to enter my qualifications, my educational achievements, my endorsements and public profile, the existence of my children and their relationship to me, and my spousal arrangements into the public record. It matters that I might be able to insure myself and others against future unemployment, ill health, or damage to my property and have my rights thereby recorded in the public record. It matters that I may at once register my voice as to how the institutional structure might be modified, have recourse to arbitration to settle disputes, and have a certain security in doing so.

This is the major challenge presented to any given institutional system - how it can provide an integrated system for conducting political-socioeconomic affairs. If it doesn't, it will struggle to offer the complementarities which attract the ordinary individual in such weighty decisions. The state has an advantage in this respect over blockchain technologies as an institutional system and system for public records for it has had some thousands of years to discover and develop institutional capabilities, but there is no reason in principle other than the current monopolisation of violence by the state (and willingness to use it) which prevents their similar development.

\subsection{The properties of "fit" institutional systems}

In any evolutionary system such as a society with competing institutional systems, selection pressure is harnessed into selection and retention based on the "fitness" of the units of selection. Those which are "fit" are selected by the evolutionary process and retained, those which are not are deselected and discarded. Even the anarchist utopia has a degree of brutality to it - institutional competition like biological evolution is "red and tooth in claw"- but only in a metaphorical sense, for selection pressures in this system are (in principle) exerted by the free decisions to associate and interact according to rules to which all relevant individuals agree.

From the above considerations, we now understand 
better the factors which cause selection pressures to be exerted differentially in the process of institutional evolution in political-socioeconomic systems organised by blockchain technology. Those institutional structures, and the technology (blockchain or the state) employed for keeping public records within them will be selected and retained which meet requirements for reciprocity, security, usability, integrity and retention and which provide sufficient complementarities between the range of interactions which might be engaged in and entered into the public record. At present, the State remains unchallenged in the wholesale sense, for in addition to the violence it may visit on those who resist its coercion, blockchain technologies have been focused on facilitating particular interactions in relative isolation and their ability to meet requirements has been constrained.

However, as their capacity for exclusion to enforce reciprocity, security, integrity and retention grow, and as their usability improves, and as the range of interactions which might be conducted within them and entered into the public record grows, we can expect the "fitness" of institutional structures founded upon blockchain technologies to improve. As we move into the future and toward a more recognisably anarchist society based on free mutual association, we can expect those blockchains or states associated with institutional systems which are more usable, which offer greater enforcement of reciprocity, security, integrity and retention, and which offer a greater range of politicalsocioeconomic interactions which might be conducted within them and entered into their public record to be selected and retained by the process of competition and evolution of institutional systems.

\section{Conclusion: the road to utopia}

It is unlikely that the state will ever be entirely superseded by another institutional system in the process of societal evolution. What is more likely is that either it will make use of violence to coerce adherence to certain or all of its institutional system and public records, or it will enter with some degree of success into the competition between institutional systems alongside blockchain technologies. But the challenge posed to the State simply by the emergence and potential of blockchain to facilitate interactions entered into freely according to rules agreed to freely means that in some sense, the anarchist utopia has become a little closer than before.

What we have done in this essay is investigate the technology which has made this possible, and consider the dynamics of a society organised using blockchain technology. We have seen what it means that blockchain is a distributed ledger technology which allows a collective to formulate, promulgate, keep and verify an institutional system and public record of interactions within it, and how it is revolutionary because it (in principle) makes exit an increasingly feasible option at the level of entire societies. We have applied the theory of evolutionary institutional political economy and economic psychology to study the dynamics of a society in which institutions associated with blockchains or the state are competing with one another. We discovered that those institutional systems selected and retained by the evolutionary process in society which meet requirements and provide complementarities. That is to say, those institutional systems will be more likely selected and retained as systems for politicalsocioeconomic interaction which provide reciprocity, security, usability, integrity and retention as well as a greater range of interactions which might be engaged in and entered into the public record.

The anarchist utopia of a society in which individuals are entirely free to elect to associate themselves with others and interact with them according to a set of rules to which those others agree is not here yet, and it probably never will be in all likelihood; but it has been made more possible, and we can expect the challenge to be increasingly presented to the state to reform in order to become more competitive with blockchain in a society which is constantly evolving.

\section{Mathematical Appendix}

The population of individuals $i$ is $N$. The set of demes $D\left(I_{r}\right)$ \& $D$ associated with an institutional system

$I_{r} \in I$ for interaction and the public record $r$ for doing so which is compiled either by blockchain or the state. We say that some action $a_{\mathrm{i}}$ on the part of an individual constitutes an agreement to interact within a particular institutional system if it is contained within the set $S\left(I_{r}\right)$ of actions which satisfy the rules of proper action which constitute the institutions of a particular system and which will be entered into the public record $r$. Thus, we may define a deme $D\left(I_{r}\right)$ to be the set of individuals who agree to interact within a particular institutional system, that is,

$$
D\left(I_{r}\right)=\left\{\mathrm{i} \in \mathrm{N}: a_{i} \in S\left(I_{r}\right)\right\}
$$

Thus, the rate of selection of the institutional system $I$ at any given time $t$ may be defined by the rate at which individuals who aren't currently are now deciding to interact within it and have their interactions recorded on its public record $r$. That is, the rate of selection of the institutional system $I_{\mathrm{r}}$ and its public record $r$ (either state or blockchain) is given by

$$
\frac{d|\mathrm{D}(\mathrm{I})|}{\mathrm{dt}}=\left|\mathrm{D}_{\mathrm{t}}\left(\mathrm{I}_{\mathrm{r}}\right)\right|-\left|\mathrm{D}_{\mathrm{t}-1}\left(\mathrm{I}_{\mathrm{r}}\right)\right|
$$




$$
\frac{d|D(I)|}{d t}=\left|\left\{\mathrm{i} \in N: a_{\mathrm{i}}^{\mathrm{t}} \in S^{t}\left(I_{r}\right)\right\}\right|-\left|\left\{\mathrm{i} \in N: a_{\mathrm{i}}^{\mathrm{t}-1} \in \mathrm{S}^{\mathrm{t}-1}\left(\mathrm{I}_{\mathrm{r}}\right)\right\}\right|
$$

where, following convention, $|\mathrm{X}|$ denotes the cardinality (number of elements) of the set $\mathrm{X}$, and we are allowing for the possibility that the set S(I_r ) of proper actions per the institutional structure I_r which will be recorded in the public record $\mathrm{r}$ varies over time. What we can see clearly here is that the rate of selection of the institutional system $\mathrm{I}_{r}$ by the process of evolution is dependent on the rate at which individuals alter their behaviour. Specifically, it relies on the rate at which individuals are deciding to change their behaviour from not agreeing to be part of the institutional structure

$$
\mathrm{a}_{\mathrm{i}}^{\mathrm{t}-1} \notin \mathrm{S}^{\mathrm{t}-1}\left(I_{r}\right) \rightarrow a_{i}^{t} \in S^{t}\left(I_{r}\right)
$$

It is discussed in Markey-Towler (forthcoming) ${ }^{5}$ that this will, inter alia, be dependent on whether or not a state of substitutability exists between the two courses of action. This will be the case if the outcomes $\mathrm{g}_{a \mathrm{i}}{ }_{\mathrm{i}}^{\mathrm{t}} \in S^{t}\left(I_{r}\right)$ the individual expects to attend from interacting within the institutional structure $I_{r}$ to be as preferable as those the individual expects to attend from not interacting within the institutional structure $\mathrm{I}_{\mathrm{r}} \mathrm{g}_{a \mathrm{i}}^{\mathrm{t}-1} \in S^{\mathrm{t}-1}\left(I_{r}\right)$

$$
\mathrm{g}_{a \mathrm{i}}{ }^{\mathrm{t}} \notin S^{t}\left(I_{r}\right) \sim \mathrm{g}_{a \mathrm{i}}{ }^{\mathrm{t}-1} \notin S^{t-1}\left(I_{r}\right)
$$

If this is the case then it is demonstrable (see MarkeyTowler (forthcoming)) that it is technically possible to induce the individual to opt to interact within an institutional system and have their interactions recorded on its public record.

This may not be the case, and barriers might exist which prevent the selection of a particular institutional system, if a state of substitutability does not exist. This might be the case either due to basic non-substitutability or the existence of complementarity.

If two institutional systems are non-substitutable, then the outcomes $\mathrm{g}_{a \mathrm{i}}{ }^{t} \notin \mathrm{S}^{\mathrm{t}}\left(\mathrm{I}_{\mathrm{r}}\right)$ the individual expects to attend from interacting within the institutional structure $I_{r}$ are not as preferable as those the individual expects to attend from not interacting within the institutional

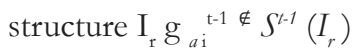

$$
\mathrm{g}_{a \mathrm{i}}{ }^{\mathrm{t}} \in S^{t}\left(I_{r}\right) \nsim \mathrm{g}_{a \mathrm{i}}{ }^{\mathrm{t}-1} \notin S^{t-1}\left(I_{r}\right)
$$

This might be the case because rather than making complex tradeoffs between alternative courses of action, individuals are applying cutoffs contained within rules for eliminating courses of action.

Complementarity exists if the outcomes expected to attend upon the taking of two actions $\alpha, \alpha^{\prime}$ together $\mathrm{a} \supset \alpha, \alpha^{\prime}$ are more preferable than those expected to attend upon taking one alone, $\alpha \subset \mathrm{a} \not \supset \alpha^{\prime}$, that is, if $\mathrm{a} \supset \alpha$

$$
g_{a}>g_{\mathrm{a} \not \supset \alpha^{\prime}}
$$

This might present a reason that a state of substitutability might not exist between two institutional systems, as would be the case if there were some action $\alpha^{\wedge}$ which might not be included within any feasible action which would constitute agreement to the institutional structure $\mathrm{I}_{\mathrm{r}}$. If $\alpha^{\prime} \subset a_{\mathrm{i}}^{t} \notin S^{t}\left(I_{r}\right)$ but $\alpha^{\prime} \not \subset a_{i}^{t} \in S^{t}\left(I_{r}\right)$ and this were complementarity with some other action $\alpha$ then by definition we would find a non-substitutability between the two institutional systems and a barrier to the selection of $I_{r}$ by the process of evolution.

1. For a more technical introduction to blockchain technology, see the original Bitcoin white paper by Satoshi Nakamoto (2008), or the excellent overview by Kariappa Bheemaiah (2015).

2. To put it in a technical manner, the transactions costs of the keeping and verification of public records collectively rather than by a centralised authority were far too high to justify not having a government for that purpose (Catalini and Gans, 2017).

3. "Crypto-secession" as we might call the Exit from adherence to the institutional structures of States in favour of those organised by blockchain technologies.

4. See Markey-Towler (2017b) which is an informal discussion of certain points in Markey-Towler (forthcoming) on this point of subtlety.

5. Markey-Towler, (2017b) provides a non-technical exposition of these factors. 


\section{References}

Ackerman, Peter and Kruegler, Christopher (1994) Strategic

Nonviolent Conflict, University of

Michigan Press, Ann Arbor

Allen, Darcy W. E. and Berg, Chris and Lane, Aaron M. and Potts, Jason, (2017) "The

Economics of Crypto-Democracy", Available at SSRN: https:/ / ssrn.com/ abstract $=2973050$

Almudi, Isabel and Fatas-Villafranca, Francisco and Izquierdo, Luis R., and Potts, Jason

(2017) "The economics of utopia: a co-evolutionary model of ideas, citizenship and socio

political change", Journal of Evolutionary Economics, 27(4), pp.629-662

Almudi, Isabel and Fatas-Villafranca, Francisco and Potts, Jason (2017) "Utopia competition:

a new approach to the micro-foundations of sustainability transitions", Journal of

Bioeconomics, 19(1), pp.165-185

Berg, Alastair and Berg, Chris, (2017) "Exit, Voice, and Forking", Available at SSRN:

bttps:// ssrn.com/ abstract $=3081291$

Bheemaiah, Kariappa, (2015) "Why Business Schools Need to Teach About the Blockechain",

Available at SSRN: https: / / ssrn.com/ abstract $=2596465$

Catalini, Christian and Gans, Joshua S., (2017) "Some Simple

Economics of the Blockechain",

Rotman School of Management Working Paper No. 2874598; MIT Sloan Research

Paper No. 5191-16. Available at

SSRN: https://ssrn.com/abstract $=2874598$ or bttp:// $d x$.doi.org/10.2139/ssrn.2874598

Commons, John R., (1924) The Legal Foundations of Capitalism, Macmillan, New York.

Davidson, Sinclair and De Filippi, Primavera and Potts, Jason, (forthcoming) "Blockechains

and the economic institutions of capitalism", Journal of Institutional Economics

Davidson, Sinclair and De Filippi, Primavera and Potts, Jason, (2016) 'Disrupting

Governance: The New Institutional Economics of Distributed Ledger Technology",

Available at SSRN: https:/ / ssrn.com/ abstract $=2811995$

Dopfer, Kurt and Potts, Jason, (2007) The General Theory of Economic Evolution, Routledge,

London

Earl, Peter, (1986a) Lifestyle Economics, Harvester Wheatsheaf, Brighton
Earl, Peter, (1986b) "A Behavioural Analysis of Demand Elasticities", Journal of Economic

Studies, 13(3), pp.20-37

Earl, Peter, (1990) "Economics and Psychology: A Survey", Economic Journal, 100, pp.718-55

Earl, Peter, (1995) Microeconomics for Business and Marketing, Edward Elgar Ltd., Aldershot

Earl, Peter, (2017) 'Lifestyle changes and the lifestyle selection process" Journal of Bioeconomics,

19(1), pp.97-114

Habermas, Jurgen, (1962) Structural Transformation of the Public Sphere, MIT Press, Cambridge,

Massachusetts

Hamilton, Walton H. (1919) "The Institutional Approach to

Economic Theory”, American

Economic Review, 13(1), pp.92-95

Hart, Herbert L.A., (1961) The Concept of Law, Oxford University Press, Oxford

Hartley, John and Potts, Jason, (2014) Cultural Science, Bloomsbury, London

Hirschman, Albert, (1970) Exit, Voice and Loyalty, Harvard University Press, Cambridge,

Massacbusetts

Hodgson, Geoffrey, (1998) "The Approach of Institutional Economics" Journal of Economic

Literature, Vol. XXXVI, pp.166-192

Hodgson, Geoffrey, (2004) The Evolution of Institutional Economics, Routledge, London

Hodgson, Geoffrey, and Knudsen, Thorbjorn, (2010) Darwin's Conjecture, Cambridge

University Press, Cambridge

Landes, David S., (1969) The Unbound Prometheus, Cambridge University Press, Cambridge

Lawson, Tony, (2016) "Comparing Conceptions of Social Ontology: Emergent Social Entities

and/ or Institutional Facts?" Journal for the Theory of Social Behaviour, 46(4), pp.359-399

MacDonald, Trent J. (2015a), "Spontaneous Order in the Formation of Non-Territorial

Political Jurisdictions", Available at SSRN: https:/ / ssrn.com/ abstract $=2661250$

MacDonald, Trent J. (2015b), "Theory of Non-Territorial Internal Exit", Available at 
SSRN: https:// ssrn.com/ abstract $=2661226$ or

bttp:/ / dx.doi.org/10.2139/ssrn.2661226

MacDonald Trent.J., Allen Darcy W.E., Potts Jason, (2016)

"Blockechains and the

Boundaries of Self-Organized Economies: Predictions for the

Future of Banking", In:

Tasca P., Aste T., Pelizzon L., Perony N. (eds) Banking

Beyond Banks and Money.

New Economic Windows. Springer, Berlin

Markey-Towler, Brendan, (2017a) "Law of the jungle: firm survival and price dynamics in

evolutionary markets", Journal of Evolutionary Economics, 26(3), pp.655-696

Markey-Towler, Brendan (2017b) "How to win customers and influence people:

Ameliorating the barriers to inducing behavioural change", Journal of Behavioral Economics

for Policy, 1(Special Issue: Behavioral Policy and its Stakeholders), pp.27-32

Markey-Towler, Brendan, (2017c) 'Economic Dark Matter: On the Theory of

Substitutability", Available at SSRN: https://ssrn.com/ abstract $=2971744$

Markey-Towler, Brendan (forthcoming) An Architecture of the Mind, Routledge, London

Marshall, Peter, (1992) Demanding the Impossible, A History of Anarchism, Harper Perennial, New

York

McCloskey, Deidre, (2006), The Bourgeois Virtues, University of Chicago Press, Chicago

Metcalfe, Stanley, (1998), Evolutionary Economics and Creative Destruction, Routledge, London

Metcalfe, Stanley, (2008), "Accounting for economic evolution: Fitness and the population

method", Journal of Bioeconomics, 10(1), pp.23-49

Murray, Cameron and Frijters, Paul, (2017), Game of Mates, Brisbane

Nakamoto, Satoshi, (2009), "Bitcoin: A Peer-to-Peer Electronic Cash System", Available at

URL: https:// bitcoin.org/bitcoin.pdf

Nelson, Richard and Winter Sidney, An Evolutionary Theory of Economic Change, Harvard

University Press, Cambridge, Massachusetts

North, Douglass C., (1990) Institutions, Institutional Change and Economic Performance, Cambridge

University Press, Cambridge

Olsen, Mancur, (1965) The Logic of Collective Action,
Harvard University Press, Harvard

Ostrom, Elinor, (1990) Governing the Commons, Cambridge

University Press, Cambridge

Page, Karen M. and Nowak, Martin A. (2002) "Unifying Evolutionary Dynamics", Journal of

Theoretical Biology, 219(2), pp.93-98

Price, George R. (1970) "Selection and Covariance" Nature, 227, pp.520-521

Price, George R. (1972a) "Extension of covariance selection mathematics", Annals of Human

Genetics, 35(4), pp.485-490

Price, George R. (1972b) 'Fisher's 'fundamental theorem' made clear", Annals of Human

Genetics, 36(2), pp.129-140

Searle, John (2010) Making the Social World, Oxford University Press, Oxford

Williamson, Oliver E. (1985) The Economic Institutions of Capitalism, MacMillan, London

Witt, Ulrich, (2008) "What is specific about evolutionary economics?" Journal of Evolutionary

Economics, 18(5), pp.547-575 